\section{TURISMO E COMUNICAÇÃO \\ Estudo do Turismo na História da \\ Comunicação no Século XIX}

Carlos Marcos Avighi!

RESLMO: O estudo do turismo à lư da história da cultura e da comunicaça no século XIX mostra que scmpre houve uma relação inscparável entre turismo e comunicação. Isto porque o turismo opera $\mathrm{cm}$ contextos organizados pcla comunicação e sc apóia. hasicamentc. no imaginário.

PALAVRAS-CHAVE: Turismo: comunicacão: século XIX: história da cultura. História da Comunicação: turismo: século XIX.

ABSTRACT: The stude of tomrism under the light of the histony of cullure

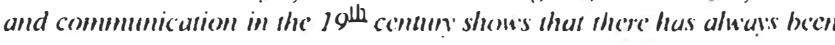
an inscparoble relationship) bentecen tentrism and commmenication. This is duc to the fact that tourisin exists in historical conte exs that are orgunized by commmenication and stands, basically; on subjectiviness

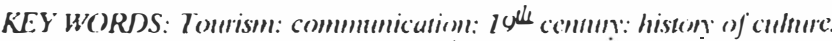

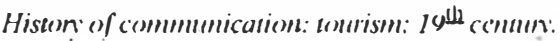

\section{INTRODUÇĀO)}

() que há de comum entre a Víage'nn de Muniquc a (jênova de Heinrich Heinc, e as reportagens de Henry Stanley sobre a África no New York Herald? - O primciro descreve uma viagem sentimental, o segundo uma expedição. Viagem é termo que pede adjetivo c turismo pode significar coisas diferentes conformc a época e o lugar... (CASSOU, 1967). A viagcm sempre acompanhou o scr humano. () turismo. no século XIX, é fenômeno de europeus é de norte-americanos. Mas, sc o assunto

1 Doutor cm Ciĉncias da Comunicacão. Professor de "História da Cultura e da Comunicação". do Iepartamento de (omunica̧̧ão c Arte da I scola de Comunicaçòes c Artes da LSP.

End. para corresp.: I ( A/LSP - I)cpartamento de (omunicacāoc A Arte - A . Prof. lúcio Martins Rodrigucs. 443. 2c andar. Prédio (cntral - 055(18-(K)). Sào Paulo - SP - Brasil. éturismo, daqui em diante a palavra viagem se refere a elc, salvo indicação em contrário.

Voltando à pergunta inicial, Hcine c Stanlcy tornaram públicas suas diferentes experiências através da mídia impressa c, assim, cada qual a sua maneira estimulou o imaginário para as viagens. Nāo quer dizer que escrevessem com a intenção do marketing turístico ou que todos os leitores pudessem repetir o itincrário. É fato, porém, que tais publicaçōes participavam e incrementavam uma atmosfera predisposta à curiosidade e à viagem. Esta, se realizada, adotava a forma acessível do turismo.

O que ressalta é a intervenção da comunicação, enquanto nı́dia impressa, a mais avançada da época, c como organização simbólicà, na sensibilização para as viagens, para o turismo.

\section{ESTUDO DO TURISMO NA HISTÓRIA DA COMUNICAÇĀO) DO SÉCULO XIX}

A revolução industrial criou ou ampliou, nas capitais curopéias e nas principais cidades dos Estados Unidos, camadas sociais afluentes e educadas, ávidas por viagens é por informaçiócs sobre sua regiāo e sobre o mundo. E aptas a consumí-las de acordo com suas possibilidades. No conjunto, cedo descobriram o valor das viagens c passaram a concorrer com a aristocracia e com os barōes das finanças, não raro formando um perfil turístico próprio.

A urbanização do século XIX gerou cspaços simbólicos que atrairam viajantes. Ao mesmo tempo, delimitou o ambientc do circuito mais rápido da informação. Periódicos, cspecializados ou não, livros, guias e mapas informavam sobre os avanços no setor de transportes e descreviam viagens em cidades e terras conlíguas ou no além-mar.

O telégrafo e as agências de notícias alimentavam o fluxo de dados e os relatos sobre áreas próximas ou distantes, recentemente alcançadas pelo expansionismo das potências. Junto com a arte e a literatura, predispunham às viagens. Até hoje o turismo ć indissociado da comunicação.

A imprensa tornara-se acessível a quase todas as pessoas, graças à disseminação do ensino e ao baratcamento do produto decorrentc das transformaçōes tecnológicas na tipografia. () uso do vapor nas impressoras foi demonstrado possivel $\mathrm{cm} 1811 \mathrm{e}$ utilizado pela primcira vè três anos depois no The Times, aperfeiçoando-se a partir de 18.30 c permitindo tiragens mais rápidas. Na década de $18(6)$, inovaçôes mecânicas, principalmente o linotipo, aceleraram estes avanços, aumentando cm cinco 
vezes a velocidade da reproduçào, de modo a atender a crescente demanda do material impresso.

O periódico ficou $80 \%$ mais barato, sobretudo com o aparecimento do anúncio, a fonte real do lucro. Émile (jirardin, fundador do La Presse, introduziu o anúncio moderno, "simples e objetivo", e a ele scguiram-se agências de anúncios, abrindo caminho para a entrada da publicidade na promoçāo turística. 2

Ao mesmo tempo, apareciam revistas especializadas, que através de dados e de ficçāo, tratavam do mundo mais distante e do universo vizinho dos leitores, falavam de viagens e de viajantes. Os títulos destas revistas sugerem com clareza a intençāo, como, por excmplo, a Revuic des Deux Mondes ${ }^{3}$, o Musée des Families c o Magasin Pitoresque (CASSOU, 1967:25).

Um dos impulsos mais fortes na relação entre comunicaçāo c turismo foi dado pela introduçāo da fotografia na imprensa, em especial na ilustraçāo de roteiros e outras matćrias específicas. Ao obter a primeira fotografia em 1835, Daguerre facultava o aparecimento da fotogravura e, portanto, da imprensa ilustrada, que levava ao limite o contato entre o objeto e o leitor. Desde o início, a fotografia deparou-se com uma ampla procura, tornando-se, em meados do século, um dos excelentes negócios da comunicaçāo, como Nadar bem o comprecndeu. A articulaçāo da fotografia com a imprensa culminou com um dos produtos mais expressivos da interlocuçāo entre turismo c comunicaçào, o cartāo-postal.

Incentivado no espaço urbano, o turismo do século XIX dependia cada vez mais dos avanços nos sistemas de reproduçāo gráfica. Multiplicavam-se os guias impressos, as tabclas de transportes, os mapas, enfim, um material de comunicação que facilitava o deslocamento do turista e, acima de tudo, constituía um forte apelo às viagens.

A reprodutibilidade alcançada pela revoluçāo tecnológica na imprensa disseminava livros, como o Memórias de um Turista, de Stendhal, e as gravuras de Dixon Denham e de Livingstone da África.

A Comunicaçāo e o Turismo mantêm laços apertados com o mundo) urbano, meio propício à vivacidade da informaçāo e "habitat" das camadas

2 Sobre a revolução tecnológica na tipografia no século XIX. ver resumo cm TERR()L (19:4:30-3).

3 A Revue des Deux Mondes cra voltada para os cstudos comparados. o que remetc aos estudos sobre out ras naçöes (BRUNEL. ct. al.. 1(9)()). sociais predispostas a viajar, em parte encorajadas pela comunicaçāo. $\mathrm{O}$ século XIX é o século da urbanização. No início do século, 23 cidades cem mais de cem mabitantes e somentc Paris e Londres abrigavam mais de 500 mil pessoas; um século depois eram 49 as cidades desse porte e subiram para 135 as que possuíam mais de cem mil pessoas (REMOND, 1986:137).

Para as camadas pobres, a cidade industrial era um mundo de miséria, como bem o descreveu Charles Dickens em Tempos Dificeis ${ }^{4}$. Mas para os industriais, financistas, aristocratas e, em larga medida, para as camadas médias a cidade oferecia a face progressista c cosmopolita, elementos subjacentes à comunicação e ao turismo. Esse lado luminoso atraía turistas do mundo civilizado e fascinava a elitc provinciana, que de tudo tomava conhecimento através da mídia impressa e jamais esquecia a viagem à capital. Flaubert imortalizou tal apelo $\mathrm{cm}$ Madame Bovary.

Por si, a cidade é um espaço de comunicaçāo, ć um espaço simb6lico, encerra estilos de vida, de relaçōes, de trabalho c de lazer. É conjunto de lugares e de histórias que envolvem os habitantes é os visitantes. Além disso, contém outros espaços de comunicaçāo, aqueles que a corporificam e promovem o encontro c a descoberta.

Os espaços de comunicação urbanos foram revalorizados pelas reformas urbanísticas do sćculo XIX em quase todas as capitais européias. Em Paris, o barāo Haussmann recupcrou os bosques de Bologne e de Vincennes e abriu os largos bulcvares que convidavam ao passcio e instalavam os cafés, pontos obrigatórios de turismo. Viena passou pela mesma transformaçāo (SHORSKE, 1990).

As novas plantas destacavam o tcatro e a ópera e multiplicavam a opção turística com bibliotecas e museus reformados, monumentos e galerias. De 90 mil visitantes em 1848, a Royal Academy passou a receber 400 mil em 1870. A torre Eiffel é de 1889. Em Londres o Palácio de Cristal

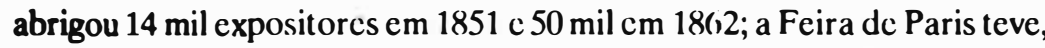
em 1855, 24 mil expositores e 50 mil cm 1867; a Feira do Centenário, de Filadélfia, em 1876 recebeu 300 mil turistas, entre cles a família real do Brasil (HOBSBAWM, 1979). Esses cventos eram divulgados pela mídia do mundo civilizado e até Euclides da Cunha comentou a Exposiçāo de Saint-Louis no artigo Civilização, publicado no jornal $O$ Estado de São Paulo em julho de 1904 (CONTRASTES...: 1975) ${ }^{5}$.

4 A mortalidade infantil é um dos índiccs mais expressivos ua condicảo de vida nas cidades industriais. I: $m$ Nova lorque foram 120/14.5 os ólıitos por mil nascimentos em 1810. passando para 180 por mil em 1850 . 220 por mil cm $18(x)$ e 26,0 po mil cm 1870 (G)ITIA 1981:172).

5 Ver também estudo a respeito cm AVI(illI (1'87) 
Ao lado desses, out ros espaços de comunicaçào ofereciam divertimento. Era o século da música ligcira c de Strauss, do "can-can" e dos cabarés parisienses que se tornaram célebres. Difundiam-se os pontos de compras, prenunciando a sociedade de consumo, com o aparecimento, na Europa e nos Estados Unidos, das grandes lojas como o Bon Marché (MILLER, 1981), o Whiteley's Universal Emporium c o Wanamakers (HOSBSBAW, 1988:51). Nos centros urbanos alcançados pela industrialização processava-se a base da futura sociedade de massa, a unificaçāo do público. () intercàmbio de experiências sobre os espaços de comunicação deixava à vontade o cidadáo urbano e cosmopolita nas cidades estrangeiras que visitava.

()s ritmos da cidade e da comunicaçào aceleravam-se mutuamente, incentivando a informação turística. A imprensa conquistava maior pe. netraçāo, ainda que de modo socialmentc difercnciado. (Os produtos impressos podiam ser usufruídos graças à política de ensino dos países industrializados (c, excepcionalmente, atć de um império tradicional, como o Austro-Húngaro). Também a educaçāo cra um benefício urbano, embora nāo se restringisse às grandes cidades.

Promovia-se a alfabctizaçào obrigatória em massa, atualizando uma iniciativa que, no ()cidente protestante, remonta ao século XVI. No século XIX o ensino tendia à laicidade, das escolas clementares às universidades. A disseminaçāo da csicolaridade manifestava-se no crescimento de espaços de comunicaçào, a começar pela ampliaçào de bibliotecas e incremento dos acervos e com o aumento de associaçōes científicas.

A escolaridade fornecia o conhecimento, conferia uma visāo cosmopolita e incentivava o hábito das viagens c a curiosidade pelo que pode haver e ser visto "no outro lado". As viagens de verào da classe média constituíam um momento importante do ano. Entre os que tivessem 0 privilégio da formação superior, a viagem cra ocasiāo obrigatória. ()s jovens completavam os estudos universitários com o "grand tour" (BRUNEL et al., 1990:22), costume existente desde o século XVI, mas, no século XIX, diversificado no próprio país c nas áreas abertas pelo colonialismo.

A Itália ainda era uma atração forte, mas desde o século XVII enfrentava a concorrência francesa e, pouco depois, suíça, ibćrica, russa, sem falar no Norte da África e no ()riente Próximo. () estudo de desenho nos currículos permitia que se copiassem e, eventualmente, divulgassem pela imprensa estilos arquitetônicos, monumentos, traços culturais dos lugares visitados.

As representaçōes mentais do século século XIX foram agitadas pelo romantismo e alimentadas pelas artes e pela mídia impressa. Empe- hados em recusar as disfunçócs da socicdade industrial, os románticos buscavam referências no passado das nacionalidades c na voga do exotisbuscas regiôes intocadas pcla civilizaçáo. Viajar, tal como hojc, cra mo das regienacināo e o poćtico. Viajar cra parte de ser romântico. Ocupado em ouvir os "direitos do coraçāo" c na procura da felicidade, o Ocupatico viajava para "observar e sentir" lèitores predispostos a repetir a experiência de acordo com suas possibilidades.

Alguns esperavam encontrar na vida rural as culturas que ainda reproduzissem costumes antigos, os fundamentos "do povo", logo estudados pelo folclore. Recuperavam-se paisagens, agrárias ou incultas, e homens supostamente intocados pela civilizaçáo industrial c que conservariam símbolos ancestrais de uma ética perdida nos grandes centros. Desenvolvia-se uma literatura voltada a temas das origens das nacionalidades, com Nicolau Gogol, Walter Scott e tantos outros. Fenimore Cooper transpôs para a ficção o fim do último "bom sclvagem" c Emerson anotou o êxtase diante do oestc bravio da América do Norte; $\mathrm{cm}$ ambos os casos referiam-se a lugares para onde as ferrovias levavam centenas de turistas.

Românticos e nāo românticos encontravam o exótico na própria Europa. Atrativo mais forte quanto mais acessível devido à contigüidade.

Goya informava sobre os costumes e os cenários espanhóis, para onde Bizet transferiu o "ethos" de sua criaçào. Flaubert avançou mais e fe\% um roteiro pelo Mediterrâneo. Conservando a aura clássica, o Mediterrànco fora atualizado pela rebcliāo grega contra o império otomano na constelaçāo das revoltas das nacionalidades. Byron celchrou o lcvante e Delacroix denunciou a repressảo turca no quadro $A$ Mlatança de Quíos.

A amplitude de informaçōes promovida pela mundializaçáo aceclerada exacerbava a curiosidade sobre as culturas náo-curopćias. Quase sempre visōes fantasiosas, pelas quais a arte c a litcratura forjavam uma imagem orientalista, como demonstra o helo ensaio Oricntalismo, de SAID (1990). O (Oriente Próximo c a África do Norte cram desafios sedutores. O contato com o universo islâmico tornara-se menos refratário, em razão da educação sccular e da socicdadc industrial laica. A arte, a fotografia e a mídia impressa estimulavam a vontade de ver "in loco" monumentos, cidades, homens e mulheres diferentes.

Os governos colonizadores incrementavam a imagem orientalista ao carregarem para as metrópoles peças, as vèes monumentos inteiros, da cultura material dos povos colonizados. Ao praticarem a lransferéncia

6 Para a relaçảo entre romantismo c viagcns, ver ( ASSOL (1)(,7:26,-7) 
da política colonial para a política cultural, transformavam símbolos de culturas remotas em símbolos do imaginário curopeu. () estrangeiro visitava Paris, via o grande obelisco) de Ramsćs II na praça da (oncórdia e, depois, com o turista parisiense poderia apreciar o outro obelisco de Luxor no contexto original ${ }^{7}$.

As especialidades acadêmicas c scus irmãos gêmeos, os tratados, logo se voltaram para os cstudos de "outros povos" e deram "status" c incentivo ao interesse por lugares extra-curopeus. As colctâncas de folclore, as conclusōes de Schlicmann em Tróia, os avanços da cgiptologia eram vulgarizados pela imprensa, ao mesmo tempo em que se recditavam livros antigos sobre descobertas c viagens.

A unificação do mundo (paralcla à unificação do público) foi um dos fatos mais importantes a intervir na cultura c na comunicaçã () do século XIX. A geoestratégia e a intcrnacionalização dos negócios, provocando as guerras, que quase scmpre os acompanham, e a internacionalizaçāo do trabalho, definiram o mais claro sinal da mundialização na ćpoca - o nascimento de associações mundiais de trabalhadores e de associaçōes assistenciais. As duas primciras internacionais comunistas são do século passado e a Cruz. Vermelha Intcrnacional é de $1860($. Significativo é que as acompanhou a idćia de uma língua comum a lodos os homens e que teve como primcira tentativa o idioma Volapuk (de "world speak") c, com maior sucesso, o Esperanto, de 1880$)(H() B S B A W N, 1979: 84)$.

A comunicação internacionalizada, cm geral sujcita a manipulaçōes, começava a promover intercâmbios mundiais. Em maio de 1893 jornalistas de todo o mundo reuniram-se em ('hicago para discutir a situação do jornalismo e sua relaçāo com os dircilos humanos. Em julho do mesmo ano, surgia a L'Union Intcmationale des Associutions de Presse, que duraria até 1935 (WEI, 1975:115).

Além das ferrovias, as linhas tclegráficas e os cabos submarinos compunham zonas, cada vez mais extensas, incorporadas às potências. A instantaneidade da informaçāo reforçava a magia por lugares distantes, ensejando a ilusāo de cstar lá, naquclc mundo inćdito. Idcalizado por Samuel Morse em 1832, o telćgrafo transmitiu a primcira mensagem cm 1835. Entre 1840/1850 esicndia os fios por áreas sempre maiores. A instalaçāo de cabos submarinos internacionais começou na década de 1850, constituindo-se ligaçāo fundamental com o mundo nāo curopeu, chegando até Singapura (H()BSBAWN, 1979:72-7). () tclégrafo scm fio

7 Ramsés II erigiu dois obcliscos na cntrada do lemplo de Amon. $\mathrm{cm}$ l uxor. Lm ficou

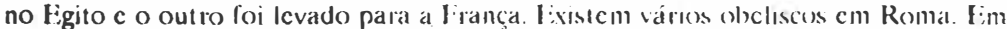
Londres está o de Tutamés III. de 180 toncladas viria a assegurar as transmissoes em fins do século, desde que Marconi, em 1895, enviava os primciros sinais Morse pelo novo sistema. Scis anos depois, asse

As agências de notıcias, filhas diletas do tclégrafo, centralizavam e distribuíam a massa de informaçōes diariamente recebidas. A comunicação, que organizava a socicdade industrial, agora organizava o mundo âa qua pela revoluçāo industrial. Percebendo o potencial do tclégrafo, Charles-Louis Havas fundou a primcira agência de notícias em 1835, seguido de Bernard Wolff e de Paul Jules Reuter, na Europa, c, nos Estados Unidos, pela Harbows Ncws Association, cm 1848, antepassado mais remoto da atual Associated Press 8

A filtragem operada pelas agências noticiosas decorria de interesses governamentais e privados c, também, da necessidade de ordenar miriades de dados de inúmeras procedências. () dispositivo comercial e organizador da comunicação encontrou ĉmulo nas agências de viagenens. Também estas dirigiam o viajantc, scparavam o supćrfluo c o incoveniente, "criavam o roteiro". Em 1845, o inglês Thomas Cook fundou a primeira agência de turismo (PIRES,1991:26), c publicou o primciro guia de viagens, o Handbook of Trip .

A editoraçāo difundia um novo gênero, o da litcratura das viagens pelas regiōes circunvizinhas e por tcrras distantes, lcma mais freqüente e noticiado. O Itinerário dc Paris a Jenusalém, de ('hatcaubriand, $A$ Viagem Sentimental, de Stcrnc, o panflcto Pesbre Bélgica! de Baudclairc, o estudo Michelet na Itália, de J-M Carré, para citar alguns entré outros arrolados por BRUNEL et al. (199):24-5).

Outros materiais impressos divulgavam aventuras, exploraçōes e roteiros. Livros, periódicos, guias c mapas davam conta das viagens de Livingstone e Stanlcy, Mungo Park e Burton. Fantasia c fato, cxagcro e rigor pouca diferença faviam na cxacerbaçáo de visōes c no descjo de viagens dos leitores.

A civilizaçāo logo sucedia às exploraçōes c, com cla, a scgurança e o conforto. O turis o em regioes distantes cra uma "aventura" que, no máximo, simulava o exotismo genuíno experimentado pelos desbravadores. A aventura era substituída pelo pitoresco. Aos postos militares, c aos caminhos dos funcionários coloniais scguiam-sc os hotéis ce os rotciros, devidamente protcgidos. Só alyuns cxilados da sociedade industrial se instalavam no mcio estranho. Rimbaud comcrciou em Harrar, na Abissínia, após viaj pe a uropa, pc o Medilcrrânco, pela África no Norte e pela Oceania.

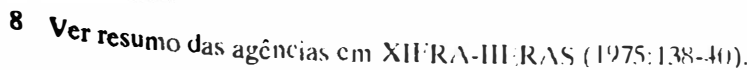


O turismo nāo reproduzia as viagens estimuladas pelas artes e pela comunicação. () roteiro turístico territorializa, desenha um espaço protegido para o forastciro, perpassa o meio quase sem tocá-lo, de modo que o turista está e, ao mesmo tempo, nào está no ambiente que visita.

Neste sentido, o hotel era um prolongamento do rotciro, um território que separava o estrangciro da rua, do nativo. () turista ficava rest rito a um único contato direto: com a profusāo de símbolos extraídos da regiảo e ditribuídos pelos hotéis, pelos restaurantes (em geral situados na csfera física do hotel) e outros lugares. () camarciro, nativo domesticado, era um desses símbolos.

A segunda metade do século XIX é a época do "grand hotel", testemunha da intencionalidade turística, pois era infra-cstrutura $e$, ele próprio, atração turística. Construído nas metrópoles, foi copiado (nesta época de reprodutibilidade) nas zonas colonizadas com a devida cor lıcal, como o Shepheard's, no Cairo, em 1841, o (irand Hotel ('ontinental, de Port Said, em 1880, o ()riental Hotcl, cm Bangcoc, de 1887. É fácil verificar como o "grand hotel") seguia as pegadas do avanço colonial, distribuindo-se por Casablanca. Trípoli, Istambul, Bombaim, Hong Kong, Shangai. () Great Eastern, de Calcutá, foi construído cm 1850), época em que a Inglaterra fixava domínio sobre a India.

Assim como as informaçóes que as estimulavam, as viagens encontravam na revolução tecnológica $\mathrm{cm}$ geral c na revoluçāo das tecnologias da comunicaçāo em particular o suporte matcrial que as realizava. As possibilidades técnicas das viagens pareciam nāo tecr limites, como sugere Júlio Verne no Volta ao Mundo em 80 Dias. Afinal, a Aída, de Verdi, fo encenada às margens do Canal de Suc\%, quando de sua inauguraçāo. As linhas férreas e sua condição indispensável, as linhas telegrálicas, desvendavam sucessivas áreas, contíguas ou nāo, para o deleitc do viajante.

Ao lado da segurança e do conforto, o transportc forma o trinómio do aparato turístico e, no século XIX, a ferrovia se crigiu no veiculo terrestre por excelência; em muitos lugares cra o único vcículo moderno. Unificou o planeta. Era elemento imprescindível para a circulação da produção em massa e, portanto, para a expansão do mercado mundial. Em 1882, os trens transportavam perto de dois bilhóes de pessoas por ano 10 .

9 Ver reportagem (Grand Hond: a ricla nos palúcios de) Oricnes (GRANI) Hotel. 1990). 10 Ver tabelas sobrc transportcs no sćculo XIX (HI)I3SIBAWM. 1971):319: HOBSBAWAM, 1988:48-9/95/40(3), c mapas do transportc fcrroviário europeu (MOZ.ARF́. 1965:252-3)
A partir de 1860 , a ferrovia Paris-Viena passou a utilizar carros A pan", que se tornariam a grande atraçäo da viagem quando os "pallmo estenderam até Istambul. Era o tempo das transcontinentais. () trilhos Unidos foram cortados por trilhos, promovendo o turismo interEstados Uniante podia ir de Nova lorque a Sāo Francisco em scte dias mo. O viajan on cenários do ( )este sem precisar sair da composiçāo, acresaprecian vagōes-leito, de vagōes arrendados a famílias, de carros-restaucante. Criaram-se os "palacc-cars", adaptados com aınplas vidraças para que os passageiros desfrutassem do espetáculo sclvagem dos parques que os passas grandes planícics c da Sirra Nevada ( F( )HLEN, 1989:30-40)

A comunicação logo se apropriou da estrada-de-ferro. ()s periódicos publicavam reportagens sobre as possiblidades técnicas da ferrovia e sobre o espetáculo que, no caso dos Estados Unidos, descortinava ao viajante. No New York Herald de 3 de maio de 1869), o jornalista descreve a travessia ferroviária das montanhas Rochosas, falando $\mathrm{cm}$ "visão magnifica", rios, gargantas, proc\%as da engenharia c assim por diante (FOHLEN, 1989:41)

O trem distribuía periódicos pelas estaçôes do interior c algumas companhias introduziram o vagāo de lcitura, verdadcira biblioteca de viagem. Exprime a confluência turismo c comunicaçāo c a disseminaçāo da imprensa no século passado. Era também um bom negócio: a Roulledge's Railway Libran' acabou se desvinculando da ferrovia que a originou e evoluiu para a cditora Routledge', que ainda cxistc.

\section{CONCLUSÃO}

A comunicação reordenou o espaço e o tempo do mundo criado pela revolução industrial c o turismo foi um dos produtos desta reordenaçāo. Onde os efeitos da industrializaçāo cram mais frágcis, a comunicaçāo e o turismo, em graus difierentes, sc retardaram. () Brasil forneceu turistas à Europa, mas nada teve de comparável ao turismo curopeu e norte-americano ou às árcas ocupadas pelos paísc's industrializados. Ao se identificarem, no século passado, as raíces do turismo no Brasil, não há como ignorar a ausência gencralizada de condiçōes para sua operaçāo, como demonstra PIRES (1\%)1).

Além da relação direta, dada pela cstruturaçào social c pela tecnologá, comunicaçāo e turismo operam no universo simbólico das pessoas. Vai muito além das motivaçōes de làcr. A comunicaçāo enscja em larga medida as viagens, seja incorporando signos de "status" e de consumo, seja incentivando a imaginação e o desejo. Também esscs fatos já são identificados no século passado. 
A força propulsora da comunicaçào nào se resumia à propaganda O imaginário das viagens era sensibilizado pelo livro, pelas reportagens, pela reprodução de imagens, todoeste material divulgado péla revolução na imprensa do século XIX.

Assim como o turismo, a comunicaçáo florescéu no terreno das transformaçōes sociais e dos avanços lecenológicos do século passado. Ao contrário do turismo, porém, a comunicaçāo moderna náo só decorria das mudanças promovidas pela revoluçāo industrial, mas agia sobre o novo universo que se formava. Ao organizar a sociedade, a comunicaç̧ão organizava o turismo.

E uma relaçào inerente e prevalece hoje. T()FFLER (199):427) aponta o que chama "os três $T$ " - turismo, telecomunicaçóes e transportes - como os fatores que devem acclerar o processo econômico na bacia do Pacífico neste final de nosso século.

\section{REFERENCIAS BIBLIOGRÁFICAS}

AVIGHI. Carlos M. 1987. Eiuclides da ('unha jomalista. São Paulo - Tesc (doutorado), ECA-USP.

BRUNEL. Jean ct al. 1990. Quc c' litcratura commaruda Trad de ('élia Berrentin. Săo Paulo/Curitiba: Pcrspectiva/Univ. Fed. do Paraná. (Coleção I'sludos)

CASSOU, Jean. 1967. Du voyage ou tourisme. ('ommunic atioms. Paris: (entre d fitudes des Communications de Masse/Licole Pratique des I latules Itudes. n. 10

CONTRASTES e confrontos. 1975. I ist. crítico de Araripe Ir... Rio de Jancisc: Record. FOHLEN, Claude. 1989. O faresestc $(186(1) / 189(1)$ ). Trad. de Paulo Neves. São Paulo: Cia das Letras.

GRAND Hotel: a vida nos palácios do () riente. 1)90. Imten irtil: n. 124

GOITIA. Fe rnando C. 1981. Brele históric del turbanisme. Madrid: Alianca Isditorial.

HOBSBAWM, Éric. 1979. A era do capital - 1848/1875. 2 cd. Trad. de Luciano Costa Neto. Rio de Janciro: Paz e Terra.

1988. A era dosimpírios - 1875/1914 Trad de Sicni M. ( ampos c Yolandas de Tolledo. Rio de Janeiro: Paz e Terra.

MILLER Michacl B. 1981. The ben murchí: bourgcois culture and the department store (1869/1920). New .Jerscy: Princeton Liniversity Press.

MOZARE. Charles. 1965. Os burgheseses à comctuista de munde) (1780/189.5). Trad. de Marieta A. Magalhães (iodinho. I isboa: (osmos. (Cileção Rumos do Mundo)

PIRES. Mário J. 1991. Hosspedes, hospedeires e viculuntes no siculo XIX: raizes do turismo no Brasil. Săo Paulo - Tesc (I)outorado). I ( 'A-LSP.

REMOND. René. 1986. O século XIX - 1815/1914. 2 ed. Trad. de Ir rederico Pessoa de Barros. Såo Paulo: Cultrix.

SAID. Edward. 1990. Orientealisino - () Oriente como invenção) do (Bcidente. Trad. de Tomás Rosa Bueno. São Paulo: Cia. das l ctras.

SHORSKE. Carl E. 1990. Vicna fin-de-siccle: política e cultura. Trad. de Denise Botimant. Såo Paulo/Campinas: Cia. das I etras/Lnicamp.

TERROU. Fernand. 1964. A infonnaçüo. Trad. de Geraldo (ierson de Sowza. São Paulo: Difel.

TOFFLER, Alvin. 1991. Powershift - As mudanças do poder. Rio de Janciro: Record.
. Aliberdade dc infonnaçio: um problema internacional. In FISCHER H.D. MERRILL. J. (orgs.). Comunicasùo intensacional - Mcios canais e funç̄es. Trad. de Edilson Alkmin Cunha. Såo Paulo: Cult rix.

MTRAS HERAS, Jorge. 1975. A infonnnasor de Gaståo Jacinto Gomes. Sảo Paulo/Rio de Janciro: Ldusp/Cult rix. 